\title{
ALONSO SÁNCHEZ COELLO Y JUAN DE AUSTRIA: UN RETRATO DE CORTE REDESCUBIERTO *
}

Don Juan de Austria (1545-1578), hijo natural de Carlos V, fue visto por primera vez en la Corte española por su hermanastra Juana de Austria, Princesa de Portugal, en Valladolid, en mayo de 1559. Juana, que actuaba como regente de España durante la marcha temporal de su hermano Felipe a Inglaterra, representaba a la Corona en el Auto de Fe convocado por la Inquisición el día 21 de mayo, domingo festividad de la Santísima Trinidad. Don Juan asistió también a este acto junto con su tía adoptiva, Magdalena de Ulloa. Según cuenta la tradición, la princesa Juana transgredió la etiqueta de la Corte y abrazó al joven de catorce años delante de su sobrino, el infante don Carlos, y de los cortesanos. Hasta este momento la existencia de don Juan había sido objeto de numerosos comentarios en el círculo de la Corte, en donde había sido considerado como algo desconocido.

Don Juan, hijo del emperador y de su amante Bárbara Blomberg, había nacido en Ratisbona en 1547 e inmediatamente después de su nacimiento fue entregado a la custodia de Luis Quijada y su mujer, Magdalena, que se encargaron de su más temprana educación en la localidad de Villagarcía, cerca de Valladolid. Felipe II, tras regresar de su viaje por Inglaterra y los Países Bajos reconoció oficialmente, como hermano suyo, al hijo natural del emperador. En diciembre de 1559, el cardenal Granvela escribió al rey de España una carta en la que decía: «escuche Su majestad sobre darle una casa al hijo natural del emperador» ${ }^{\text {. }}$ Ante esta sugerencia Felipe II nombró tutores de don Juan a Luis Quijada, mayordomo al Conde de Priego, caballerizo mayor a Luis de Córdoba y a Juan de Quiroga su secretario. Desde este momento don Juan de Austria tuvo, aunque con algunas limitaciones, el rango de Infante de Castilla. Recibía el tratamiento de excelencia en vez de el de alteza, tampoco tenía derecho a aposentarse en el palacio ni podía sentarse con la familia real detrás de la cortina en la tribuna de la Capilla Real.

En febrero de 1560, la que sería tercera esposa de Felipe II, Isabel de Valois, hija de Enrique II de Francia y Catalina de Medicis, fue recibida por el rey y su Corte en Guadalajara. Este matrimonio selló el tratado de Chateau-Cambrésis, firmado en abril de 1559 e inauguró un tiempo de paz entre Francia y España, a la vez que inició un período de importante actividad cultural en la Corte española, establecida entonces en Toledo. Con Isabel llegaron a España numerosos artistas como Sofonisba Anguissola, dama italiana que impartía lecciones de pintura a la reina, también llegaron el portugués Manuel Denis y el flamenco Jooris van der Straeten ${ }^{2}$. En esta época el retratista oficial del rey, Antonio Moro, regresó a España por segunda vez y realizó los cuadros de la familia real entre los que se encontraban el de Juana de Austria (Museo del Prado. Inv. N. 2112) y el de la nueva reina, Isabel de Valois, vestida con un espléndido traje rojo carmesí que simbolizaba su amor por Felipe II (Colección Várez Fisa, Madrid). Aquel mismo año Alonso Sánchez Coello, principal discípulo de Moro en

\footnotetext{
- Este estudio se basa en las investigaciones que realicé sobre este retrato en 1995, conservado entonces en la Colección de Alice Ledebur, en Viena. Mis conclusiones suponen un trabajo independiente al de la Dra. Stephanie Breuer-Hermann: Pinturas de Cuatro Siglos, Madrid (Caylus Anticuario S.A.), 1997. Quiero agradecer el apoyo recibido por parte de la Dra. Eve Borsook y del Dr. Alfred Rosenauer. Igualmente al Sr. D. José Antonio de Urbina por su permiso para publicar este retrato, y a Ana García Sanz por la traducción de este artículo.

Correspondence de Granvelle, Bruselas, vol. V, p. 671, citado en W. Stirling Maxwell, Don Juan de Austria, 2 vols. Londres, 1883, p. 34.

2 María Kusche, «Sofonisba Anguissola en España. Retratista en la corte de Felipe II junto a Alonso Sánchez Coello y Jorge de la Rua», Archivo Español de Arte, n. ${ }^{248,1989}$, pp. 391-420; Annemarie Jordan, Retrato de Corte em Portugal. O legado de Antonio Moro, 1552-1572, Lisboa, 1994, pp. 128-135, 151-154.
} 
Flandes y en Portugal, y Jooris van der Straeten realizaron varias copias de este cuadro de la reina, que fueron enviadas como regalos a la Corte francesa ${ }^{3}$. (Colección Várez Fisa, Madrid y en paradero desconocido). Moro retrató también a Felipe II, al infante don Carlos y, posiblemente a don Juan de Austria, sin embargo estas obras se encuentran actualmente en paradero desconocido.

En 1560, Alonso Sánchez Coello, aún no era pintor oficial del rey y trabajaba al servicio de Juana de Austria. En este momento pintó el retrato de Don Juan (óleo sobre lienzo), que ahora nos ocupa, que puede ser fechado poco después de la introducción oficial del infante en la corte (fig. 11, Museo Soumaya, Ciudad de México) ${ }^{4}$. Se trata de un gran retrato ceremonial, de 144,5 x 69,2 cms, que presenta al recién reconocido príncipe como Infante de España. Este cuadro está relacionado con el pequeño grupo de retratos (de medio cuerpo y de cuerpo entero) que Sánchez Coello pintó en sus primeros años en Valladolid, a donde llegó desde Portugal, en 1557, para unirse a la Corte de Juana en aquella ciudad. En este grupo se incluyen el retrato del infante don Carlos, como el nuevo Júpiter español, (Museo del Prado. Inv. n.. ${ }^{0} 1136$ ) ${ }^{5}$ y los dos retratos de Juana como regente, hoy en el Schloss Ambras en Innsbruck (Inv. n. ${ }^{\circ}$ GG 3127) y en el Museo de Bellas Artes de Bilbao (Inv. n. ${ }^{\circ}$ 90/15). Sin embargo el retrato de don Juan pudo haber sido pintado en Toledo, en el momento en que la Cortes acordaron aceptar el juramento de lealtad del infante don Carlos, un acọntecimiento en el que don Juan tomó parte activa, cabalgando al lado de don Carlos hacia la catedral y sentándose en público entre Felipe II y doña Juana de Austria.

Este retrato muestra el conocimiento que Sánchez Coello tenía de las primeras obras de Antonio Moro, especialmente de los retratos de los príncipes adolescentes, que habían sido adquiridos para las galerías oficiales, tales como él del príncipe Juan de Portugal, obra de Moro y su taller, fechado en 1552 (Hampton Court. Inv. n. ${ }^{\circ}$ 1488) ${ }^{6}$. Sánchez Coello eligió en este ejemplo ampliar el modelo de tres cuartos, usual en Moro, al de cuerpo entero, un recurso al que Tiziano había sacado partido por primera vez en sus retratos de Carlos $\mathrm{V}$ y que Coello utilizó al conocer sus retratos conservados en la Colección Real española. El uso del formato de cuerpo entero en los retratos ceremoniales de corte fue una de las soluciones pictóricas utilizadas por Tiziano, que tuvo mayores repercusiones en la retratística de los Habsburgo.

Este cuadro de don Juan fue realizado para ser presentado oficialmente y todas las soluciones formales que Sánchez Coello utilizó en él subrayan esta intención. La calidad en la ejecución es excelente; el pintor se deleita en la representación gráfica de las lujosas vestiduras de seda, de color amarillo mostaza con adornos bordados en plata y seda negra. Como es habitual el príncipe viste las prendas de moda a finales de la década de los 50: un justillo con el pecho acolchado, con las mangas muy ornadas y decorado con pequeñas cuchilladas, calzas con bragueta y cuchilladas, y zapatos de piel, también con decoración de cuchilladas, teñidos para hacer juego con el resto de la indumentaria. El par de guantes de piel, en su mano

3 Para más información sobre estas copias ver Annemarie Jordan, Court Painting in Portugal. The Legacy of Anthonis Mor (1552-1572), de próxima aparición en 1999.

4 Incluso en una fecha tan tardía como 1568, cuando Sánchez Coello estaba ya trabajando para Felipe II, se le nombra como Alonso Sánchez, pintor de la Serenissima princesa. (Archivo General de Simancas, CMC, 1. época, leg. 1031, sin foliar).

5 Sánchez Coello cobró 20 ducados en 1568 por dos retratos de don Carlos (óleo sobre lienzo), uno de medio cuerpo y otro de cuerpo entero que pudo haber pintado entre 1557 y 1567 (Archivo General de Simancas, CMC, 1. época, leg. 1031, sin foliar).

6 Jordan, 1994, pp. 53-62, fig. 4. 
izquierda, son un símbolo de su rango y estado de príncipe, mientras que la daga corta dorada y la espada que porta son emblemas visuales de sus responsabilidades futuras como guerrero y soldado, un papel que desempeñó heroicamente en 1571 como vencedor de la batalla de Lepanto contra los turcos. El infante luce un importante número de joyas: un inusual y extravagante collar de oro con grandes perlas, todas ellas diferentes y entrelazadas con ramilletes de minúsculas cuentas de oro en relieve, y unas treinta y cinco joyas, semejantes a clavos de oro, que están cosidas alrededor del jubón a modo de botonadura. El uso de estas piezas de oro aumenta la elegancia de su indumentaria en la que el mismo traje es ya de un tono dorado. Esta pintura resulta algo ostentosa y obviamente debió realizarse para ser mostrada y exhibida públicamente en la Corte.

La actitud del personaje que posa con la mano colocada sobre la cadera derecha, con una apertura exagerada entre los dedos índice y corazón, es una característica que Sánchez Coello muestra a menudo en sus retratos de príncipes y gobernantes. El modo en como la espada atraviesa en diagonal la mitad inferior del lienzo, acentúa la tridimensionalidad de la composición y trasmite al espectador la existencia de un segundo plano. Sin embargo es muy poco frecuente en Sánchez Coello, la colocación de la pierna y pie derechos en el ángulo derecho del lienzo. Se trata de una reinterpretación de fórmulas que fueron anteriormente utilizadas por Tiziano, por ejemplo en el retrato de Felipe II que pintó en Augsburgo, fechado hacia 1548-51 (Museo del Prado, inv. n. ${ }^{-}$411) y posteriormente por Antonio Moro en su primer retrato de Maximiliano II, de los que han llegado hasta nosotros, también pintado en Augsburgo en 1550 (fig. 3, Museo del Prado, inv. n.․ 2110). La representación de cuerpo entero de Alejandro Farnesio, pintada por Moro en 1557 (Museo de la Academia de Bellas Artes, Parma), es un ejemplo muy cercano al de don Juan de Austria de Coello, sin embargo no parece ser que influyera directamente en él.

Igualmente, en esta pintura de don Juan, se evidencia el conocimiento de Sánchez Coello de las soluciones llevadas a cabo por algunos pintores contemporáneos como Giovanni Battista Moroni (1524-1578), cuyas composiciones, en el aspecto formal y en el técnico, fueron imitadas a menudo en los retratos ejecutados para los Habsburgo y ciertos clientes de la aristocracia, tanto en España como en los Países Bajos, por pintores como Tiziano, Antonio Moro o el mismo Sánchez Coello. El bergamés Moroni demostró, en su retrato de Gian Gerolamo Grumelli, Caballero en rojo, fechado en 1560, su familiaridad con el retrato español, lo que no es especialmente peculiar ya que las provincias del norte de Italia se encontraban bajo la influencia española, principalmente en la forma de vestir y en la etiqueta, que fueron adoptadas por la aristocracia (fig. 12, Bérgamo, Colección del Conde Moroni) Además, durante este período fue muy habitual el intercambio de tendencias en los retratos de corte entre España y el norte de Italia.

En el retrato de don Juan de Austria prevalecen, las influencias italianas por encima de las fórmulas tomadas de Moro. Sánchez Coello pudo conocer la obra de Moroni a través de los trabajos de Sofonisba Anguissola, quien llegó a España en 1559 para trabajar para Isabel de Valois, y permaneció en la Corte hasta $1573^{7}$. Sin embargo la exagerada pose del infante es un ingenio del pintor para atraer sutilmente la mirada del espectador hacia el cuadro, al mismo tiempo que logra así resaltar la arrogancia y el sutil desdén del orgulloso joven.

\footnotetext{
7 María Kusche, «Sofonisba Anguissola, retratista de la corte española», Paragone, n.. 509-511, 1992, pp. 3-34; «Sofonisba Anguissola. Vuelta a Italia. Continuación de sus relaciones en la corte española», Paragone, n.․ 513, 1992, pp. 10-35; «Sofonisba Anguissola al servizio dei re di Spagna», Sofonisba Anguissola e le sue sorelle, Cremona, 1994, pp. 89-116.
} 


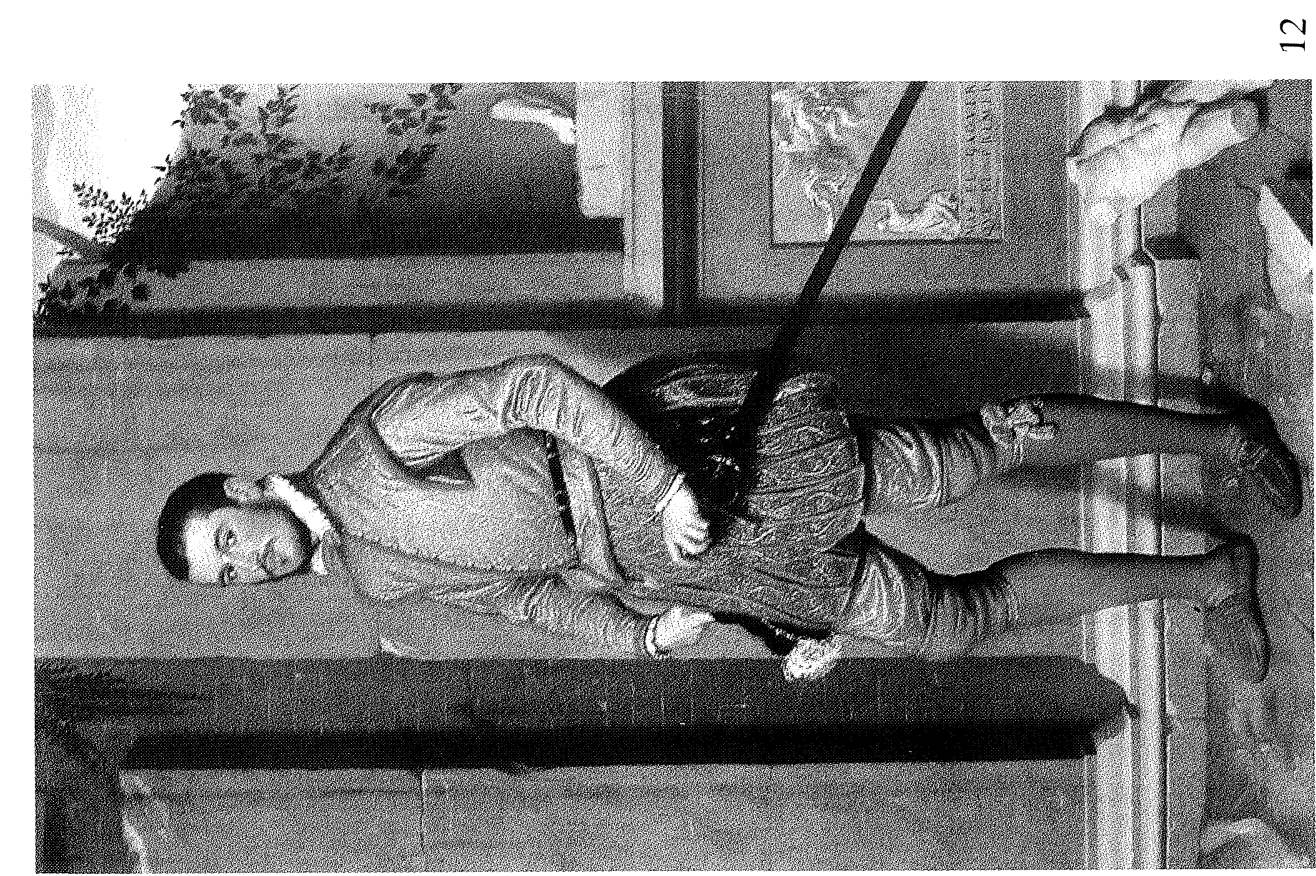

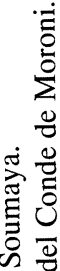

ญํํ유

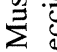

80

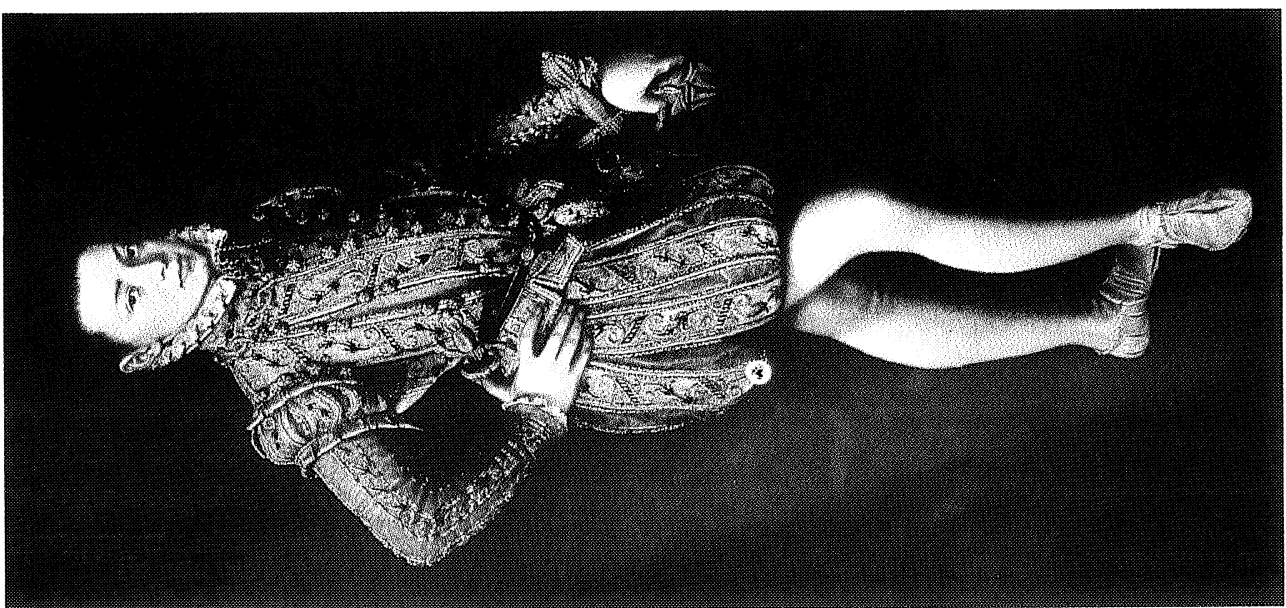

这

里

密

芑

sิ

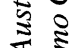

\&

ฐิ

จิ

2

官

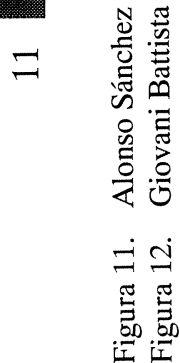


Más cercano, y quizá igualmente influyente, es el retrato de corte del bufón Pedro Herrez, más conocido como Perejón, que sirvió en la Casa del infante don Carlos y fue pintado por Antonio Moro en 1560, mientras la Corte residía en Toledo (fig. 14, Museo del Prado, Inv. N.․ 2107) ${ }^{8}$. Aunque no pertenecía socialmente a esa clase, Moro pintó a Perejón como si de un aristócrata se tratase. En esta obra Moro jugó con las fórmulas del retrato de Corte que él mismo había inventado. Moro hizo algunos cambios que transformaron la representación del bufón dándole la apariencia de un príncipe. Perejón aparece en su estancia, ligeramente girado hacia el espectador y con un pequeño espacio tras él. Esta fórmula fue imitada por Coello al colocar a sus personajes en un claro primer plano que acortaba la distancia entre el retratado y el espectador. Los fuertes contrastes entre luces y sombras es una de las grandes preocupaciones en la obra de Moro, así como los fuertes contrastes de negros, blancos y amarillos; sin embargo la fluidez de la pintura refleja el contacto directo de Sánchez Coello con la obra de Tiziano. La disposición del príncipe, en un espacio ambiguo sin ninguna definición de perspectiva, es indudablemente influencia del retrato de Perejón. Algunos de los cuadros que Moro hizo de personajes de la aristocracia y de la familia real, en su breve segundo viaje a la península Ibérica, han llegado hasta nuestros días (fig. 13). Desgraciadamente, otros ejemplos de esta época desaparecieron en el incendio del palacio de caza de El Pardo en 1604. Por lo tanto podemos suponer, con certeza, que fueron más obras de las que conocemos actualmente, las que influyeron en este retrato de don Juan.

En 1564, Sánchez Coello decidió utilizar la misma técnica, paleta y composición, que había utilizado con don Juan, en el retrato nupcial del infante don Carlos, enviado a la Corte de Viena en 1564 (fig. 15, Kunsthistorisches Museum, Viena, Inv. N. GG 3235). En este trabajo, el segundo plano quedó definido por el suelo y la pared, mientras que la actitud y disposición de las piernas fueron modificadas, posiblemente para disimular la deformidad física del príncipe, a la que el embajador imperial Adam Freiherr von Dietrichstein, hizo referencia en su carta a Maximiliano II en julio de $1564^{9}$. Es interesante ver como en estos retratos, en los que los personajes son tratados con diferente profundidad, ambos llevan la misma espada, dorada y cincelada, con un adorno de cuentas en relieve, tal vez realizada en Toledo. Pudiera tratarse de una mera coincidencia o quizá fuera un arma, perteneciente a Sánchez Coello, que se encontrara habitualmente en su taller.

El presente retrato de don Juan no está fechado ni firmado, ni tampoco aparece en los inventarios de las colecciones de Felipe II, Juana de Austria o la emperatriz María. La documentación sobre su procedencia es muy escasa y solamente es posible realizar hipótesis sobre su propietario y localización en el siglo XVI. Pudiera tratarse de un encargo para la Colección Real o para algún miembro de la aristocracia española o tal vez de una obra destinada a alguna de las cortes europeas como la francesa o la de los Países Bajos.

Sabemos que en la colección de Alfonso Sánchez Coello se encontraba en 1570 un retrato de don Juan, tal vez el que ahora nos ocupa. Esta obra fue vista en su estudio y descrita por el humanista y cortesano Diego Gracián, en un panegírico compuesto en latín y castellano ${ }^{10}$. Palomino relató, en 1724 , que tanto don Juan de Austria como el príncipe don Carlos, frecuentaban el taller de Sánchez Coello y a menudo comían en su mesa ${ }^{11}$, lo que evidencia la amistad del príncipe con el pintor. Es muy probable que Sánchez Coello conservara, en su estudio, varios cuadros de don Juan que le sirvieran de modelo para las copias que le encargaban, destinadas a las colecciones españolas y extranjeras. Un ejemplo es la representación de don Juan victorioso tras la batalla de Lepanto, pintado después de 1571, perteneciente a Felipe II (Museo Naval, Madrid). Sin embargo resulta curioso que la obra que nos ocupa no fuera nunca copiada como si lo fueron otras muchas de Sánchez Coello.

El 4 marzo de 1567, Perejón cobró 30 ducados de Francisco de Medrano en concepto de «gastos de la casa del príncipe nuestro señor». (Archivo General de Simancas, CMC, 1. ㄹ época, leg. 1031, sin foliar).

9 Gabriela Betz, Die Bildnisse des Don Carlos, Frankfurt, 1997, pp. 283-286.

10 Una transcripción completa se publicará próximamente en A. Jordan, en 1999.

${ }^{11}$ Lives of the Eminent Spanish Painters and Sculptors by Palomino, traducción de N. Mallory, Cambridge, 1987, p. 43. 

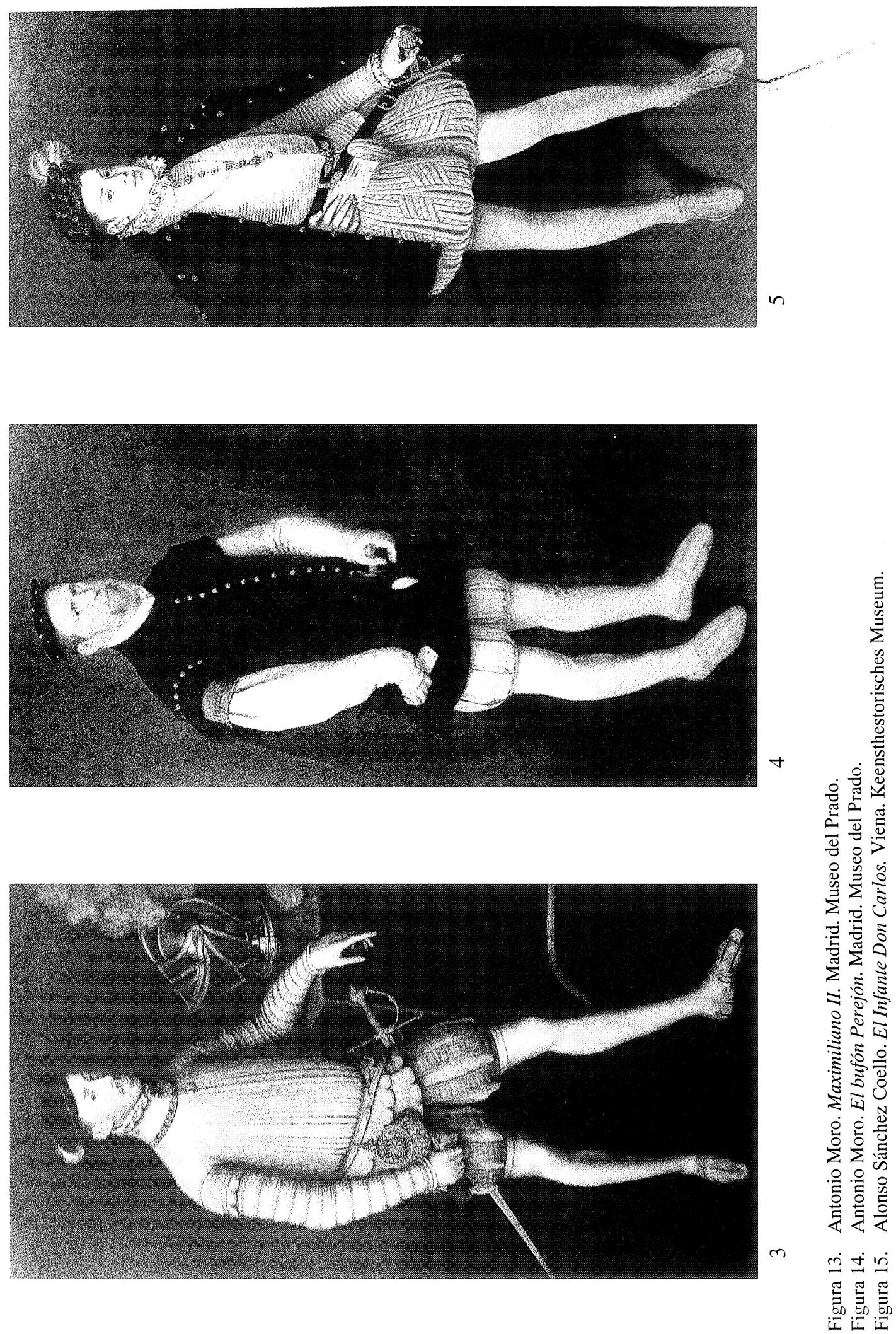
Este retrato se documenta por primera vez en el siglo XIX, en la colección de Jacques Portalés (1810-1855) y posiblemente era el mismo que se encontraba expuesto en la Galería Napoleón de París en $1810^{12}$. Este dato permite sugerir que este cuadro pudo haber salido de España durante la Guerra de la Independencia. En 1841 fue vendido a una familia de la aristocracia austríaca con conexiones en España. En esta colección particular permaneció considerado tradicionalmente como un retrato de Francisco II, hermano de Isabel de Valois e hijo de Enrique II y de Catalina de Medicis. En 1995 fue comprado por un coleccionista español ${ }^{13}$.

ANNEMARIE JORDAN

Investigadora independiente. Suiza.

\section{RECUERDOS Y BELLEZAS DE ESPAÑA Y SU RELACIÓN CON EL MEDIO FOTOGRÁFICO}

Los Recuerdos y Bellezas de España de Francisco Javier Parcerisa constituyen una de las obras más citadas en la historiografía del arte español del siglo XIX, y también una de las menos estudiadas.

Las causas del poco interés que ha despertado entre los investigadores podríamos buscarlas en su colosal extensión (12 vols.); en la escasa pasión que, estéticamente, han suscitado las litografías del autor; en lo caduco del texto, o incluso en todas ellas. Los juicios y las observaciones que sobre esta publicación se han realizado se basan en datos de trabajos pretéritos, en una ojeada fugaz o, en el mejor de los casos, en un análisis más o menos exhaustivo. Restan todavía muchas cosas por aclarar en torno a la obra de Parcerisa, cosas que seguramente matizarán algunas opiniones que tenemos de ella. Intentaremos en las siguientes páginas dar un poco de luz sobre uno de los aspectos que se nos antojan más ịteresantes, el de la relación de Parcerisa con la fotografía.

\section{Parcerisa y el daguerrotipo}

La vinculación de Parcerisa con el daguerrotipo en concreto, y con la fotografía en general, ha sido siempre fuente de malentendidos, lo cual es muy comprensible si tenemos en cuenta que es casi imposible determinar con certeza, a partir de un examen visual, si una estampa está basada en una fotografía o no. La riqueza descriptiva, el contraste tonal acentuado, el amplio ángulo de toma, la compresión de la imagen o las perspectivas muy pronunciadas nos aportan indicios de ello, pero sólo indicios. Por tanto, mientras no se aporten los originales fotográficos o datos textuales concluyentes sólo podemos hacer conjeturas, aunque estas sean muy plausibles.

Nosotros tenemos la convicción, contrariamente a lo que generalmente se ha considerado, de que las litografías de Parcerisa de estos celebérrimos Recuerdos y Bellezas de España no están basadas en daguerrotipos, o al menos no lo está su inmensa mayoría. De hecho, en ninguno de los volúmenes de esta magna obra consta que Parcerisa se basara en imágenes

12 Henry Hymans, Antonio Moro. Son oeuvre et son temps, Bruselas, 1910, p. 182: «Notice des Tableaux Exposés dans la Galerie Napoléon, París, 1810, 446. Don Juan, fils naturel de Charles-Quint».

13 En la exposición Felipe II. Un Monarca y su época. Un Príncipe del Renacimiento, Madrid, Museo del Prado, 13 octubre 1998-10 enero 1999 Cat. 95: se localiza en el Museo Soumaya de Méjico. 